\title{
ANUÁRIOS ESTATÍSTICOS retratos de diferentes épocas
}

\author{
Osvaldo Guizzardi Filho \\ Zilda Pereira da Silva \\ Ilma Edna Pereira Sidney
}

\begin{abstract}
Resumo: As estatísticas, como forma de tradução de fenômenos que o homem deseja conhecer, e os anuários, enquanto instrumentos para sua disseminação, são hoje de utilização corriqueira, sendo que muitos desconhecem o longo caminho percorrido para que se chegasse até eles. Este artigo discute a relação entre estatística, informação e conhecimento e apresenta um breve histórico da produção das estatísticas e dos anuários, em particular, do Anuário Estatístico do Estado de São Paulo, desde sua criação, passando pelas transformações que sofreu, até seu formato atual.

Palavras-chave: anuários estatísticos; informações estatísticas; disseminação.
\end{abstract}

Abstract: Statistics, as a translation of phenomena under study, and almanacs, as instruments for their dissemination, are today widely used, although many are unaware of the long process involved in their preparation. This article discusses the relationship between statistics, information and knowledge, and presents a brief history of the production of statistics and almanacs, particularly the Statistical Almanac of the State of São Paulo, tracing it back from its beginnings, through its many transformation, and up to its current format. Key words: statistical almanacs; statistical information; dissemination.

$\mathrm{T}$

odo pesquisador acostumado a utilizar informações estatísticas, certamente, tem como primeira referência para seus levantamentos uma publicação: os anuários estatísticos. Com informações sobre um tema ou um determinado espaço geográfico, eles são, sem dúvida, os meios de divulgação mais tradicionais das agências produtoras de estatísticas, apresentando coletâneas de dados em tabelas, gráficos e mapas que facilitam em muito o trabalho dos pesquisadores, principalmente daqueles que se iniciam na utilização dos números como representação do mundo. As estatísticas, como forma de tradução de fenômenos que o homem deseja conhecer, e os anuários, enquanto instrumentos para sua disseminação, são hoje de utilização corriqueira, e muitos desconhecem o longo caminho percorrido para que se chegasse até eles. É tal caminho que este artigo pretende explorar, com um olhar especial para o Anuário Estatístico do Estado de São Paulo.

\section{ESTATÍSTICA, INFORMAÇÃO E CONHECIMENTO}

A informação pode ser definida como o insumo fundamental do conhecimento. O homem, ao longo de sua vida, com base nas informações que recebe em seu dia-a-dia, apoiado na experiência das gerações que o precederam e que lhe é transmitida na convivência cotidiana com a família, a escola, o trabalho, constrói algo absolutamente seu, individual - o conhecimento -, que lhe permite agir e transformar, de alguma forma, as condições que o rodeiam. A informação, de acordo com Barreto (1994:3), "quando adequadamente assimilada, produz conhecimento, modifica o estoque mental de informações do indivíduo e traz benefícios ao seu desenvolvimento e ao desenvolvimento da sociedade em que ele vive. Assim, como agente mediador na produção do conhecimento, a informação qualifica-se, em forma e substância, como estruturas significantes 
com a competência de gerar conhecimento para o indivíduo e seu grupo."

Depois da invenção da imprensa por Gutemberg, no século XV, e com o progresso técnico observado desde então, o registro e a circulação do conhecimento produzido sobre as mais diferentes áreas cresceram exponencialmente. Numa espécie de espiral que vai continuamente se ampliando, um número crescente de pessoas tem acesso a cada vez mais informações, o que resulta na criação de novo conhecimento: é o que Wersig (1993:231) chama de despersonalização do conhecimento, fruto do desenvolvimento das tecnologias de comunicação.

Nos tempos recentes, com as novas tecnologias de comunicação e informação, com a capacidade que possui o homem de acessar e processar um volume sempre crescente de informações, existem condições para que o conhecimento possa ser incrementado de forma cada vez mais acelerada. Esta expansão quase que ilimitada na oferta de informações, que chega a todos de maneira incessante pelos mais diferentes meios, coloca uma questão, já que a produção do conhecimento não está diretamente associada à quantidade de informação disponível. É preciso que se selecionem, neste manancial, aquelas informações verdadeiramente relevantes para o trabalho que se realiza. Conforme afirma Sfez (1996:6), "todos os pesquisadores sabem: a coleta de documentos não é senão uma etapa embrionária do trabalho de organização que se lhe segue. A organização, sim, pode dar acesso a um determinado conhecimento sobre o assunto".

Com todas estas transformações, a informação e o conhecimento que dela resulta passaram a ser recursos preciosos para o desenvolvimento de indivíduos, organizações e nações, demarcando suas possibilidades de inserção num mundo cada vez mais competitivo. A expressão “economia baseada no conhecimento" é bastante utilizada hoje para identificar aqueles que se aproveitam do desenvolvimento do conhecimento, da ciência e da tecnologia, resultados que dependem do valor e da qualidade de investimentos realizados em áreas estratégicas como educação e pesquisa e desenvolvimento.

No processo de geração do conhecimento, as estatísticas são um tipo muito especial de informação, pois elaboradas em centros especializados, buscam representar, através de números, aspectos do mundo que se quer conhecer: a população por sexo e grau de instrução; o número de empresas; a produção e o pessoal ocupado em determinados setores da economia; os alunos matriculados por faixa etária num nível de ensino; a renda de uma determinada região; etc. Através destas representações, que traduzem em números realidades complexas, compostas por quantidades enormes de indivíduos, ${ }^{1}$ governos, empresas, cientistas sociais, sindicatos e organizações não-governamentais podem planejar e controlar suas atividades, ou conhecer aspectos determinados da vida em sociedade que são objeto de sua atenção. A produção destas sínteses só é possível, no entanto, se, em algum momento, for realizado um contato direto com os indivíduos que compõem os grupos que se quer estudar, sejam eles, por exemplo, a população, sejam empresas que atuam numa determinada atividade, operação esta que é realizada pelas organizações produtoras de estatística através de suas pesquisas e levantamentos.

\section{Produção de Estatísticas: Breve História}

O termo estatística tem sua origem no alemão Statistik e foi utilizado pela primeira vez pelo professor Gottfried Achenwall, em 1749 (Senra, 1998:10). De acordo com este autor, a estatística "era, a essa época, considerada como a ciência do Estado ou como a ciência que se referia ao Estado. Mais precisamente, referia-se aos acontecimentos tidos como memoráveis ao entendimento de um Estado, descrevendo-se seu território e sua população, compondo assim referências a amparar a ação de seus dirigentes. Inventariando os recursos e as forças de um Estado, oferecia-se em documentos como espelho do príncipe, tomando-se o príncipe como a própria encarnação do Estado. Semelhante aos trabalhos dos geógrafos e historiadores, nesses documentos os números não são predominantes, seja por não estarem sistematicamente disponíveis, seja também por não serem considerados essenciais a uma boa explanação, o que significa dizer que, ao tempo que chamaríamos de sua proto-história, as estatísticas não estavam necessariamente associadas aos números, sendo não raro descritivas e mesmo algo literárias".

Os números só passaram a ser identificados com a produção de estatísticas com o incremento do comércio e o papel cada vez mais ativo dos Estados no controle da produção e da circulação de mercadorias, que colocaram a necessidade de se dispor de informações para o controle dos processos econômicos e sociais associados à geração da riqueza. Aquelas que são consideradas as primeiras pesquisas estatísticas foram realizadas no século XVII, na Inglaterra, tomando como base os registros de nascimentos e mortes. O primeiro Departamento de Estatísticas Oficiais foi criado em 1695, também na Inglaterra, para contabilizar as quantidades e os valores das mercadorias 
comercializadas (Porcaro, 2000:70-71). Nestes primórdios e durante muito tempo ainda, a fonte primeira das estatísticas eram os chamados registros administrativos, mantidos por empresas, para o controle de seus negócios, e por governos, para monitorar a população ou a arrecadação de impostos. Até hoje, o registro civil constitui importante fonte para o acompanhamento do crescimento vegetativo da população, ou de suas causas de morte.

A partir da segunda metade do século XIX, ocorreu a criação de uma série de organismos produtores de estatísticas, se bem que nem sempre suas existências tenham sido longas. No Brasil, ainda no Império, em 1871, foi instituída a Diretoria Geral de Estatística, antecessora da atual Fundação Instituto Brasileiro de Geografia e Estatística - IBGE, criada em 1936 com o nome de Instituto Nacional de Estatística. Logo no ano seguinte, em 1872, realizou-se o primeiro censo demográfico brasileiro (Guizzardi Filho; Conti, 2001:45). No Estado de São Paulo, a Repartição de Estatística e Arquivo, predecessora da Fundação Seade, iniciou suas atividades em 1892. Em 1894, o diretor da Repartição apresentou ao secretário dos Negócios do Interior o Relatorio do Anno de 1893, considerado o primeiro Anuário Estatístico do Estado. Este trabalho trazia, entre outras informações, o movimento de entrada e saída de imigrantes, o número de nascimentos e óbitos, o movimento dos hospitais e casas de saúde, o movimento das bibliotecas e a população da capital por cor, sexo e estado civil. Sua introdução informa a apuração de "milhares de mappas da população da ex-provincia de S. Paulo, nos tempos coloniaes, desde meiado do seculo passado até a epoca da nossa independencia", além da realização, em 1893, de um "recenseamento da população, casas e ruas da capital, que mostrasse com alguma exactidão não sómente o total dos seus habitantes, como também a sua densidade nos diversos bairros e freguesias". Este recenseamento foi realizado em período de estado de sítio, declarado em razão de ter-se iniciado, em 6 de setembro de 1893, uma revolta de parte da marinha brasileira. Estão enunciadas nesta introdução duas das atribuições básicas de um organismo de estatísticas: a pesquisa e a organização da informação.

No que diz respeito à produção da informação, os registros administrativos foram sendo substituídos pelas pesquisas primárias como principal fonte de dados das organizações nacionais de estatísticas. Estas pesquisas ganharam impulso acentuado com o desenvolvimento das técnicas de amostragem, permitindo a coleta de dados em menores períodos de tempo, com custos também inferiores. Estes avanços ocorreram principalmente depois da Se- gunda Guerra Mundial, quando o planejamento deixou de ser visto como técnica exclusiva dos países do bloco socialista, impondo-se, num primeiro momento, como necessidade para a reconstrução das economias atingidas por aquele conflito. Nos anos que se seguiram, a prática do planejamento disseminou-se, assim como a demanda por informações que o tornassem possível, o que criou as condições para a afirmação das organizações produtoras de estatísticas e a ampliação de seus quadros técnicos e do espectro de pesquisas a que se dedicavam.

Ao longo deste caminho, foram criadas instituições de pesquisa especializadas em todos os processos associados à produção e à disseminação de informações, os quais pressupõem um trabalho permanente de organização. Estes processos desenvolvem-se, permanentemente, através da interação entre as organizações e os pesquisadores que se dedicam a esta produção, intercambiando informações e formando quadros com um tipo de conhecimento bastante específico, dificilmente encontrado em outros tipos de organização, o que é característico dos centros especializados em pesquisa nas diferentes áreas do conhecimento.

\section{ORGANIZAÇÃO, PRODUÇÃO E DISSEMINAÇÃO DA INFORMAÇÃO}

A decisão sobre a produção de informações estatísticas não resulta de um processo linear, totalmente técnico. Ela é o efeito de interações, conflitos e interesses que se manifestam ao longo de uma cadeia de relações que envolvem todos os agentes associados direta ou indiretamente a esta produção, como os governos que a financiam, as instituições e pessoas que demandam os dados e os pesquisadores das mais diversas formações envolvidos nos levantamentos. Ela pode ter seu início quando um determinado agente desta cadeia de relações manifesta a necessidade do conhecimento de certos aspectos da vida econômica e social, ou quando a própria instituição se antecipa a esta demanda, ao perceber a emergência de alguns eventos cujas dimensões precisam ser mais bem conhecidas. Numa relação que se torna cada vez mais extremamente dinâmica, os centros de produção de estatísticas são instados a produzir informações sobre questões sempre novas, que vão resultando das transformações permanentes por que passa a sociedade. Decididas quais delas serão objeto de estudo, parte-se para a definição de uma série de procedimentos, como a demarcação da população que será objeto da pesquisa, o tipo de levantamento que será realizado - censitário ou amostral -, a definição 
das categorias em que serão classificados os indivíduos pesquisados e a conceituação das características ou resultados que serão levantados. Hoje, já existe extensa bibliografia originada em centros de pesquisa de atuação internacional voltada para a disseminação destas classificações e conceitos, de modo que se disponha de estatísticas comparáveis no tempo e no espaço. Porém, sempre é necessário um trabalho de adequação destas classificações e conceitos às diferentes realidades locais. Um exemplo deste trabalho é aquele realizado pelo IBGE, através da Comissão Nacional de Classificação - Concla, para a produção da Classificação Nacional de Atividades Econômicas - CNAE, baseada na International Standard Industrial Classification of All Economic Activities - ISIC, $3^{\mathrm{a}}$ revisão, das Nações Unidas, que teve sua primeira versão divulgada no final de 1994. Este trabalho acabou por ter desdobramentos, com a criação da CNAE - Fiscal, que hoje já está sendo utilizada por uma série de órgãos das três esferas de governo para a identificação das instituições que constam de seus cadastros, unificação que abre perspectivas bastante promissoras para a produção de estatísticas a partir dos registros mantidos por estes órgãos.

A clareza nestas definições é fundamental, sendo necessária sua disseminação entre as equipes que vão aplicar a pesquisa em campo, normalmente compostas por indivíduos das mais diferentes formações e experiências. Elas precisam ser compreensíveis também para os que vão responder aos levantamentos, sem o que será muito difícil a produção de resultados que possam ser agregados e comparados, bem como para os que vão utilizar as informações coletadas: os recortes feitos, as limitações dos dados em razão destes recortes e as mudanças por que eles passam ao longo do tempo precisam ser explicitados, para que os usuários não cheguem a conclusões equivocadas a partir das informações consultadas - efeito inverso ao que seria esperado delas, que é a produção de conhecimento.

Recebidos estes resultados e verificada sua qualidade, tem início um processo que, para Latour (2000), corresponde à elaboração de inscrições sucessivas, que vão refinando os primeiros números coletados e extraindo deles as informações. A partir, por exemplo, da idade ou do nível de ensino informados pelas pessoas no censo demográfico, da receita e do pessoal ocupado das empresas que responderam uma pesquisa econômica, das doenças que levaram pacientes à internação e que são registradas nos hospitais, são delimitados conjuntos que, expressos em números, fornecerão as informações necessárias ao trabalho dos diferentes analistas.
Afirmou-se, anteriormente, que os registros administrativos foram sendo abandonados como fonte de informações estatísticas, à medida que se desenvolveram as pesquisas primárias. Este abandono, no entanto, não foi total. Continua-se levantando apontamentos feitos pelos mais diferentes tipos de organizações, e que podem fornecer informações importantes sobre um número abrangente de áreas de estudo, tendo papel significativo para o conhecimento do que ocorre nos municípios, principalmente no que diz respeito à economia, já que, desde 1985, o IBGE não realiza mais os censos industriais, comerciais e de serviços. Estes registros são também importantes para a definição e o acompanhamento da realização de políticas públicas em áreas estratégicas como saúde, educação e saneamento básico.

A geração de estatísticas a partir destes registros, que não foram elaborados originalmente com este fim, exige a implantação de uma série de procedimentos. O primeiro deles refere-se ao estabelecimento das relações institucionais que garantirão o fornecimento regular dos dados, o que exige a construção de uma relação de confiança entre as partes, garantindo a manutenção do fluxo de informações e de sua qualidade. Normalmente, nas verificações dos dados recebidos que as organizações produtoras de estatísticas realizam, constatam-se inconsistências que são reportadas às fontes, exigindo, muitas vezes, checagens das informações que não seriam necessárias caso seu uso se limitasse aos fins para os quais elas foram elaboradas. Estes processos, freqüentemente, ocorrem mais de uma vez, demandando a alocação de recursos humanos e materiais que, na maioria das vezes, são escassos e não foram previstos para a produção de informações estatísticas. Há que se tecer neste trabalho, necessariamente, relações institucionais em que se evidencie a importância das informações que dele resultam, e que vão servir a um número muito mais amplo de usuários do que os normalmente previstos quando se estabeleceu a necessidade da elaboração daqueles registros.

Levantados os dados oriundos das pesquisas e dos registros administrativos, uma outra tarefa se impõe: sua organização em bases que possibilitem o processamento das inscrições de ordens sucessivas referidas anteriormente, e sua disseminação, objetivo que deve basear as ações de instituições que trabalham com a produção de informações e que vai muito além do tornar disponíveis os dados. Para que esta disseminação tenha sucesso, é preciso que se considerem as diferenças de grupos de origem, de formação e de conhecimento existentes entre os usuá- 
rios que utilizam as informações, o que vai requerer esforços para a definição de produtos diferenciados para o atendimento das demandas destes grupos. O desenvolvimento das tecnologias de comunicação e informação estabeleceu um novo patamar para a formulação destas demandas e para as possibilidades de respostas que a elas podem ser dadas. Dispõe-se agora de recursos e ferramentas para a disseminação, como a Internet e bases de dados em CDs, que colocam possibilidades quase ilimitadas de acesso e utilização das informações. Existem também instrumentos para seu armazenamento e processamento que fornecem aos usuários um grau de liberdade para o manuseio dos dados inimaginável até bem pouco tempo, o que contribui para que estes realizem exigências de informações também difíceis de se prever há alguns anos.

Ao longo da história das instituições produtoras de estatística, os anuários são uma da formas que expressam sua organização para a geração, armazenamento e disseminação de informações. São também um retrato de diferentes épocas, com suas distintas maneiras de enxergar e categorizar o mundo, que são expressas pelas estatísticas.

\section{OS ANUÁRIOS ESTATÍSTICOS}

Os anuários podem ser considerados o produto de disseminação mais tradicional das organizações produtoras de estatísticas, pensados para fornecer ao público uma seleção da ampla variedade de informações que elas, o tempo todo, coletam, processam e analisam.

Segundo Senra (1997:1), existem referências sobre a edição de anuários estatísticos já nos séculos XVII e XVIII, quando as estatísticas ainda eram encaradas como segredos de Estado. Mas é a partir do século XIX, sob a égide do liberalismo e com a afirmação da ciência como instrumento privilegiado para o conhecimento do mundo, que a produção de estatísticas cresce significativamente, expansão acompanhada pela divulgação ampla dos dados em publicações cada vez mais parecidas com os atuais anuários. Já foi feita referência, neste artigo, ao relatório apresentado em 1894, pela Repartição de Estatística e Arquivo do Estado de São Paulo, para o secretário dos Negócios do Interior, considerado o precursor dos anuários estatísticos paulistas. Aquela repartição os publicou até o ano de 1929, quando a série foi interrompida. O Anuário Estatístico do Estado de São Paulo voltou a ser impresso em 1940, sob a responsabilidade do Departamento Estadual de Estatística, criado em 1938, que os produziu até 1947, quando a publicação foi novamente suspensa: o departamento foi extinto pela Lei $\mathrm{n}^{\circ} 185$, de 13 de novembro de 1948, cujo artigo 42 autorizou o governo estadual a contratar o Instituto Brasileiro de Geografia e Estatística para a apuração dos dados estatísticos que interessassem ao Estado.

Em 1953, quando o órgão estadual foi reinstalado, com o nome de Departamento de Estatística do Estado - denominação que se manteria até 1978, ano de criação da Fundação Seade -, editou-se o anuário de 1950. Em sua introdução, chamada de "Nota Prévia", este anuário informa: "desconhecidos que ficaram desde 1946 os resultados dos levantamentos efetuados, devido à interrupção das atividades do nosso Departamento de 1948 a 1950, preocupou-nos agora a apresentação do maior repertório possível de informações relativas aos 369 municípios, por considerarmos que o balanço numérico dessas células deve ser focalizado com minuciosidades tais, que possibilitem as comparações da situação de cada uma delas em relação às demais" (Departamento de Estatística do Estado, 1950: vii).

A publicação voltou a ser interrompida entre $1952 \mathrm{e}$ 1954, sendo novamente impressa entre 1955 e 1963 e no período 1966-1973. A edição seguinte, de 1979, já foi produzida pela Fundação Seade.

O primeiro Anuário Estatístico do Brasil, dividido em três volumes, teve sua publicação iniciada em 1916, com dados referentes ao período 1908-12. Foi elaborado pela Diretoria Geral de Estatística, órgão vinculado ao Ministério da Agricultura, Indústria e Comércio. A série foi suspensa de 1913 a 1935, retornando o anuário com informações para 1936, já sob a responsabilidade do Instituto Nacional de Estatística que, em janeiro de 1938, passou a denominar-se Instituto Brasileiro de Geografia e Estatística. Para que se tenha uma idéia da importância que tinha o anuário como instrumento de divulgação das informações produzidas, logo na segunda página desta edição consta uma cópia do artigo 17, do Decreto no 24.609 de 6 de julho de 1934, que criou o instituto e que determinava: "Como obrigação essencial do Instituto e sob a responsabilidade direta da Diretoria de Estatística Geral e, solidariamente, da Junta Executiva, fica assentada, de modo expresso, a da publicação regular e uniforme da série dos anuários estatísticos do Brasil”.

Embora hoje, com o desenvolvimento das tecnologias de informação e comunicação, que potencializaram em muito as possibilidades de disseminação das informações, os anuários tenham perdido importância como ferramenta para este fim, eles continuam a ter relevância por uma 
série de razões. Como já foi dito, eles sintetizam a produção das organizações de estatística, servindo como preciosa obra de referência para os pesquisadores, principalmente quando existe a preocupação dos que elaboram os anuários de orientar os leitores, indicando quais são as outras possibilidades de obtenção de informações de que eles podem dispor, e que não estão cobertas pelos anuários, em função de seus papéis de síntese de uma produção. Como afirma Senra (1997: 2), os anuários servem como um guia, um "catálogo não apenas do conjunto selecionado de informações estatísticas nele divulgadas, mas antes de todo o sistema estatístico que lhe é subjacente, conforme visto anteriormente. Para tanto será preciso que o anuário seja equilibradamente organizado, a um só tempo explicando a lógica de seu conteúdo, reportando-se ao seu todo maior, bem como explicando as razões das ausências praticadas, que se há de crer conscientes, antes que inconscientes".

Os anuários exercem também um papel importante como documentos reveladores das mudanças que ocorrem nas organizações de estatísticas ao longo do tempo, do ponto de vista da riqueza e da organização de sua produção e da preocupação em fornecer aos pesquisadores os elementos necessários para que eles se situem entre a enorme quantidade de dados divulgados, extraindo deles as informações de que necessitam. Exercem ainda um outro papel, talvez mais significativo que o anterior, ao fornecer pistas para o conhecimento das modificações por que passa a sociedade ao longo do tempo do ponto de vista de sua organização e de suas dinâmicas econômica e social, e das maneiras utilizadas para recortá-la, categorizá-la para compreendê-la, enfim -, que são produtos destes diferentes momentos.

No Annuario Estatistico de São Paulo de 1902, por exemplo, os eleitores são classificados de acordo com as seguintes profissões: agricultores, artistas, clérigos, comerciantes, empregados públicos, industriais, jornalistas, letrados, militares e operários. Observados os números referentes aos casamentos, fica-se sabendo que, aos cônjuges, poderiam ser associados dois estados civis anteriores ao enlace: solteiro ou viúvo. A produção era classificada em três grandes grupos: agrícola, extrativa e zootécnica, sendo que a agrícola era detalhada nos seguintes produtos: aguardente, algodão, arroz, açúcar, café, feijão, milho, tabaco e vinho. No porto de Santos carregavam e descarregavam mercadorias de dois tipos de embarcações: vapores e navios à vela. Já os municípios eram financiados por receitas como o imposto de indústrias e profissões, o imposto sobre café saído do município, as rendas do cemitério, do matadouro e do mercado.

\section{O ANUÁRIO ESTATÍSTICO A PARTIR DA CRIAÇÃO DA FUNDAÇÃO SEADE}

Conforme colocado anteriormente, as transformações por que passam os anuários revelam as potencialidades e limitações dos sistemas estatísticos que estão sendo sintetizados. Isso está claramente refletido nas diversas fases da história do Anuário Estatístico do Estado de São Paulo, das quais destaca-se, a seguir, aquela ocorrida após a criação da Fundação Seade.

Com sua edição interrompida em 1973, foi só a partir da criação da Fundação, em dezembro de 1978, que o Anuário Estatístico voltou a ser produzido de forma regular e ininterrupta até os dias de hoje.

O Anuário 1979 teve o mérito de preencher a lacuna existente na divulgação das estatísticas relevantes sobre o Estado, com apresentação de séries históricas para recuperar informações do período em que ficou sem ser editado. Nessa edição, ampliaram-se de forma significativa os assuntos abordados até então, substituindo a organização por temas abrangentes do Anuário 1973 (situação econômica, social, cultural e administrativa e política) por um enfoque setorial. Os dados foram organizados em 20 capítulos temáticos: Brasil e Estado de São Paulo Indicadores Comparados, Caracterização do Território, Contabilidade Social, Demografia, Saúde, Saneamento, Emprego, Educação, Cultos Religiosos, Justiça e Segurança, Agropecuária, Indústria, Construção Civil, Comércio e Serviços, Comércio Exterior, Mercado Financeiro, Transportes e Comunicações e Energia, Preços, Finanças Públicas e Renda.

O leque de temas cobertos por um anuário reflete o conhecimento de determinada realidade, como já foi abordado anteriormente: ao longo do tempo, algumas áreas perdem relevância, enquanto novas surgem ou ganham outro significado. No Anuário de 1973, havia um capítulo intitulado Silvicultura, que deixou de ser publicado e que continha, entre outros, dados agrupados no tema Abate de Árvores, com números da produção de lenha, madeira e carvão. Parte desses dados foi incorporada, como seção, ao atual capítulo Agricultura, que abrange um conjunto mais amplo de áreas do setor primário da economia, como produção da terra, produção vegetal e produção animal. Por outro lado, na década de 90, foi incorporado o capítulo Meio Ambiente, abordando aspectos geográficos 
relevantes do ponto de vista da qualidade ambiental e da atuação da administração pública para disciplinar as diversas formas de intervenção no meio físico, com dados, por exemplo, de processos de Estudos e Relatórios de Impacto Ambiental (EIA/Rima).

Ao longo desses últimos 24 anos, a maior parte do conjunto de temas abordados no Anuário de São Paulo manteve-se constante. Foram introduzidos novos capítulos e informações e retirados dos outros poucos, o que, na maioria das vezes, deveu-se à falta de dados por perda de importância da temática, como cultos religiosos, ou à dificuldade de acesso às informações, decorrentes, por exemplo, da concessão ao setor privado dos serviços de transportes, energia e comunicações. No caso particular de energia e comunicações, isso se refletiu na ausência de informações municipais. ${ }^{2}$

Assim, o último Anuário Estatístico divulgado (2001) está organizado nos seguintes capítulos: Caracterização do Território; Demografia; Saúde; Saneamento; Meio Ambiente; Habitação; Educação; Cultura; Justiça e Segurança; Previdência; Emprego; Contas Nacionais/Regionais; Agricultura; Indústria; Comércio; Energia; Transportes; Sistema Financeiro; Comércio Exterior e Finanças Públicas.

O primeiro Anuário publicado após a criação da Fundação Seade apresentava também um formato editorial muito diverso do que ele tem hoje. Foi a partir da edição de 1980 que começou a tomar corpo o formato atual, com a definição de um padrão editorial e gráfico que, na sua essência, perdura até agora. Nessa edição, foram incorporados textos introdutórios geral e específicos de cada capítulo, com apresentação sobre o conteúdo e a organização dos capítulos, além de alguns conceitos e notas metodológicas. A apresentação tabular foi redefinida, a partir da criação de um padrão baseado nas normas do IBGE, e o item Convenções e Critérios Utilizados foi ampliado, fornecendo informações mais claras para auxílio aos usuários.

Nos anos 80 , o Anuário ocupava a posição de publicação mais importante da Fundação Seade e era o principal meio de disseminação das informações sobre o Estado. Visando seu aperfeiçoamento, iniciou-se, em 1988, um processo de avaliação que seria retomado no começo dos anos 90, revertendo no aprimoramento das edições de 1991, 1992 e 1993.

\section{Avaliações Realizadas e seus Resultados}

Em 1988, foi criado um grupo que envolveu técnicos de diversas áreas da Fundação, com objetivo de elaborar um novo projeto para o Anuário. Como resultado deste trabalho, produziu-se um exaustivo diagnóstico, que propôs diversas sugestões gerais e específicas para cada capítulo, que poderiam ser implementadas em curto e médio prazos, compreendendo: organização geral do Anuário; adoção da nova organização político-administrativa na apresentação dos dados; medidas orientadoras sobre concepção geral, estrutura e conteúdo dos capítulos; ampliação de conteúdos; coleta dos dados; etapas de produção; fortalecimento das relações institucionais com as fontes primárias; e ampliação das ações de divulgação do Anuário (Fundação Seade, 1988).

No relatório sobre a Elaboração de Novo Projeto do Anuário Estatístico do Estado de São Paulo, em 1988, ressaltava-se também a importância de manter um grupo de trabalho interdisciplinar, para acompanhar a implantação de propostas, a reavaliação permanente da publicação e dar continuidade ao trabalho apresentado.

Novas reformulações ocorreram na edição de 1991: foi realizada uma revisão ampla de conteúdo dos capítulos existentes - que resultou na agregação de indicadores e publicação de séries históricas -; incluíram-se novos capítulos (Contas Regionais, Comércio Exterior e Previdência Social, este último retomando a publicação de capítulo que integrou apenas o Anuário 1980); e alterou-se a forma de agregação dos dados para Regiões Administrativas e Regiões de Governo - até o Anuário anterior, na maior parte dos capítulos, as tabelas eram publicadas por RA e seus respectivos municípios-sede.

Na edição de 1992 do Anuário, além da ampliação de conteúdo, com a incorporação de informações sobre a Pesquisa de Emprego e Desemprego - PED e a introdução de dois novos capítulos (Meio Ambiente e Sistema Financeiro) foram incluídas, em cada capítulo, notas metodológicas e definições de conceitos, com o objetivo de fornecer aos usuários informações sobre as potencialidades e as possíveis restrições dos dados divulgados, que demandassem conhecimentos especializados, ou quando ocorressem modificações metodológicas que pudessem influir na comparabilidade das séries históricas.

No período 1993-94, foi criado um novo grupo de trabalho com a incumbência de avaliar e coordenar a elaboração do Anuário. Nessa época, estava sendo desenvolvida, na Fundação Seade, uma pesquisa sobre o Perfil do Usuário, em que o Anuário foi citado como o produto mais conhecido. A partir desta constatação, o GT Anuário demandou a realização de uma avaliação da publicação, para identificar o perfil do seu usuário e as expectativas com 
relação à publicação. A avaliação foi feita ${ }^{3}$ a partir de entrevistas em profundidade (pesquisa qualitativa), com técnicos envolvidos na elaboração da publicação e usuários dos setores público e privado, e por meio de questionários com perguntas fechadas (pesquisa quantitativa) aplicados no atendimento direto ao público e via encarte distribuído com o Anuário 1992.

Vale destacar alguns resultados deste levantamento. $\mathrm{Na}$ caracterização das empresas onde atuam os usuários, observou-se que, apesar da diversidade, as áreas de atuação e responsabilidade dos setores ou projetos nos quais se encontravam os entrevistados variavam em torno de objetivos comuns. Notou-se predomínio das áreas de sistematização e análise de dados econômicos, seguidas por aquelas ligadas a projetos de planejamento urbano municipal e regional, além daquelas responsáveis por centros de informação, dados e referências bibliográficas.

A maioria dos entrevistados conheceu a publicação no ambiente de trabalho, vinculando-a à atividade profissional e referindo-se à mesma como instrumento de trabalho. Eram antigos usuários do Anuário, e, assim demonstravam familiaridade e fidelidade ao produto. Em relação ao tipo de informações utilizadas, as mais citadas foram as dos capítulos de Demografia e Finanças Públicas, seguindo-se as de Saúde, Educação e Indústria e Emprego (Fundação Seade, 1994).

A pesquisa forneceu subsídios importantes que, somados à avaliação feita pelo GT, resultaram em algumas inovações que foram implantadas no Anuário 1993, das quais destacam-se aquelas de natureza documental, com o objetivo de dar maior acessibilidade ao seu conteúdo, como o novo padrão editorial, a re-introdução de índice de assuntos e, a mais importante, a substituição dos textos introdutórios, com caráter de apresentação de conteúdo e de esclarecimentos metodológicos, por textos analíticos. As notas metodológicas também foram adensadas, apresentando maior detalhamento, e passaram a constituir um novo capítulo, agrupando todos os temas.

\section{Diversas Versões Produzidas desde 1979 e a Situação Hoje: versão apenas na Internet}

O Anuário, como principal publicação da Fundação Seade nos anos 80, era o produto utilizado para introduzir as inovações tecnológicas do processo de produção. Desde o Anuário 1979, os trabalhos de diagramação, fotolito e impressão eram feitos na Fundação.
Em particular, este primeiro teve sua composição feita em linotipo - o que significava montar as matrizes das tabelas, caracter por caracter - na gráfica da Fundação, processo que foi realizado externamente no período 1980-84. Em 1985, o Seade retomou a etapa de composição, usando tecnologia mais moderna - as máquinas Forma Composer. Em 1988, com a ampliação dos recursos da microinformática (equipamentos e softwares), passou-se a utilizar o software de editoração eletrônica Pagemaker na diagramação do Anuário 1987, o que agilizou a etapa de finalização da publicação, com a eliminação da diagramação feita à mão. ${ }^{4}$

A introdução dos equipamentos de microinformática na Fundação teve impacto em todas as etapas de produção do Anuário 1987: o processo de elaboração foi inteiramente informatizado, desde o tratamento estatístico dispensado aos dados e variáveis primárias, passando pela substituição das tabelas e gráficos manuscritos, até a edição final do volume. Até 1986, a produção do Anuário, com elaboração manual das tabelas e composição mecânica, envolvia uma fase de conferências de sucessivas provas até obter-se a versão final, trabalho que demandava tempo e equipe consideráveis. Esse novo processo avançou em 1993, com a instalação da rede de informática, quando passou-se a produzir o Anuário integralmente em ambiente de rede, o que permitiu maior agilidade e qualidade no seu processo de elaboração.

Nesse mesmo ano, visando fornecer uma nova forma de acesso aos dados, foi elaborada a primeira versão eletrônica (em DOS) para consulta interna dos usuários e, em 1995, foi produzida a primeira versão do Anuário (1994) em ambiente Windows, disponível ao público em geral. Seguindo a política de comunicação/disseminação adotada pela Fundação Seade, com a criação do seu site, ${ }^{5}$ inaugurou-se a fase do Anuário na Internet, em 1996, disponibilizando todas as edições a partir da de 1994. Até o Anuário de 1998, foram mantidas as versões impressas e na Internet. Porém, as edições de 1999 a 2001 foram disponibilizadas apenas na Internet.

Com a multiplicação das linhas de trabalho da Fundação e a ampliação das formas de disseminação - especialmente a partir dos recursos introduzidos pela Internet -, de forma mais intensa na segunda metade da década de 90, o Anuário deixou de ser o principal meio de divulgação dos dados produzidos pela instituição. Isto resultou em restrição para implementar a proposta de constante avaliação desse produto, restringindo-se, na maioria das vezes, à avaliação dos meios de disseminação, o que, in- 
clusive, suscitou algumas discussões sobre a pertinência da manutenção de uma edição impressa.

O Anuário Estatístico do Estado de São Paulo é o produto mais tradicional da Fundação Seade. Sua elaboração sempre foi fruto de um grande esforço - característica presente na produção de todo e qualquer Anuário, dada a magnitude da tarefa - e hoje envolve cerca de 80 profissionais de diversas áreas produtoras de informações, de informática e de artes e editoração da instituição.

O esforço referido é o de procurar sintetizar um sistema, enquanto um conjunto amplo e constantemente em expansão, de estatísticas entendidas como necessárias à compreensão das mais diversas dimensões de uma determinada realidade em um certo espaço físico. As estatísticas expressam conhecimento sobre a sociedade de determinada época, daí a importância do Anuário como documento, como registro concreto da história. Ele registra transformações de toda ordem no cotidiano dos paulistas, como, por exemplo, na forma de viver e adoecer - o Anuário registrou a erradicação da poliomielite, em 1989, e o primeiro caso de Aids no país, ocorrido no Estado, em 1980 -, bem como a inauguração de um novo meio de transporte, com o início da operação comercial do metrô, em 1974 (registrado no Anuário de 1979).

Mesmo sendo instrumentos tradicionais, que ainda expressam uma forma de organização dos dados para a disseminação que pode ser considerada anacrônica, observados os recursos que as tecnologias de informação e comunicação propiciam atualmente - tabelas, organizadas de forma hierárquica por capítulos e seções -, os anuários ainda têm uma função importante a cumprir, em razão dos motivos expressos anteriormente. Torna-se necessário, no entanto, que eles sejam submetidos a processos permanentes de avaliação, no que diz respeito tanto aos seus conteúdos quanto à incorporação dos recursos propiciados pelas novas tecnologias, que estão o tempo todo passando por mudanças, e de outros que possam facilitar a navegação dos usuários pelo mar de dados que eles contêm, sem perder sua característica principal, que é, como já colocado anteriormente, a de servir como síntese da produção das organizações de estatística. Estes recursos tecnológicos fornecem as condições, inclusive, para que sejam elaboradas versões diferenciadas dos anuários, com conjuntos de dados e ferramentas para sua recuperação também diferenciados, indo da mais tradicional, que é a impressa, ao $\mathrm{CD}$ e à Internet, atendendo às demandas dos mais diferentes tipos de usuários. Estas duas últimas mí- dias não impõem as restrições que existem para a publicação impressa no que se refere ao volume de dados divulgados e ao seu manuseio, permitindo, por exemplo, a inclusão de bases de dados municipais - demanda antiga dos usuários -, cruzamento dos números divulgados para a construção de indicadores e produção de gráficos e mapas de forma interativa.

Não se pode perder de vista, no entanto, aquele que deve ser o objetivo final dos anuários: fornecer um amplo panorama das informações levantadas pelas instituições produtoras de estatística, não cabendo a eles, em função de sua periodicidade, abarcar todos os resultados desta produção, que deve ir sendo colocada à disposição do público assim que é finalizada, com o aproveitamento de todos os meios para a disseminação que hoje estão disponíveis. Como alerta Senra (1997), essas possibilidades abertas pelas novas tecnologias "exige um intenso pensar e repensar da questão de conteúdo, estabelecendo com propriedade as aproximações e os afastamentos entre os anuários impresso e em meio magnético".

\section{CONSIDERAÇÕES FINAIS}

As imensas possibilidades oferecidas pela informática e Internet na disseminação de dados e informações não tornam, por si só, inexorável a substituição do documento impresso pelo digital. Apesar dos reconhecidos ganhos na utilização das novas tecnologias - agilizam a disseminação, eliminam distâncias, permitindo acesso a indivíduos em diferentes localidades, facilitam o trabalho de pesquisadores -, não se deve restringir a publicação do Anuário ao formato eletrônico, sob o risco de promover exclusão ao desconsiderar que esse meio se limita à parcela da população que tem acesso a essas tecnologias. É necessário, portanto, reconhecer que o livro ainda é a forma mais acessível para um número maior de indivíduos, além de assegurar um registro físico, e não apenas virtual, das informações, garantindo sua preservação ao longo do tempo. Possibilitar a existência das duas formas "é almejar assegurar a indestrutibilidade do texto e de suas formas de difusão, tendo a certeza de que, enquanto objetos culturais, o impresso e o digital indiciam aspectos das sociedades que os produziram (e produzem) e em que circularam (ou circulam)" (Vidal, 2002).

É reconhecida a necessidade de permanente avaliação do conteúdo e da forma dos anuários, para que eles possam expressar os movimentos no acervo de informações e de transformações da sociedade. Senra (1997) chama 
atenção para a necessidade de se captar junto à sociedade, com maior detalhamento possível, a dimensão política - representação dos objetivos específicos - que se deseja imprimir a um determinado anuário, traduzida na seleção de variáveis que comporão o seu conteúdo. Feito isso, há que se estar atento às evoluções de demandas dessa sociedade, de modo que o anuário possa ser sempre útil, em outras palavras, estar sempre afinado com sua dimensão política. Como o anuário é uma obra de interesse de um público de amplo perfil, é de extrema utilidade o acompanhamento de como esse público, nos seus mais variados segmentos, recebe essa publicação, tarefa que deve ser assumida por um grupo de trabalho interdisciplinar, que avalie permanentemente o conteúdo do anuário e as demandas dos usuários, como na pesquisa realizada em 1993, o que traz benefícios não só para a sua produção, mas também para a definição de agenda de pesquisas que devem ser realizadas pela instituição.

\section{NOTAS}

1. O termo "indivíduo" deve ser entendido aqui num sentido amplo, compreendendo não apenas pessoas, mas também coisas e instituições das mais diferentes naturezas, como empresas, escolas, sindicatos, famílias, etc.

2. Ressalte-se o empenho da Secretaria de Energia do Estado de São Paulo para retomada da série de dados municipais sobre consumo e consumidores de energia elétrica.

3. O projeto foi executado pelo Grupo de Aferição da Central de Dados e Referência (atual Gerência de Atendimento e Disseminação de Informações).

4. Depoimentos de Neuma Maria de B. Menegatti, Cristiane de Rosa Meira e Vania R. Fontanesi.

5. Lançado em 1994.

\section{REFERÊNCIAS BIBLIOGRÁFICAS}

BARreto, A. de A. A questão da informação. São Paulo em Perspectiva, São Paulo, v.8, n.4, p.3-8, out./dez. 1994.

DEPARTAMENTO DE ESTATÍSTICA DO ESTADO. Anuário Estatístico do Estado de São Paulo: situação física, social e cultural 1950. São Paulo, v.I, 1953. 305 p.
FUNDAÇÃO SEADE. Projeto de Avaliação do ANUESP: Sumário Executivo. São Paulo, 1994. Mimeografado.

Relatório do Grupo de Trabalho Criado pelo Diretor Executivo para Elaboração de Novo Projeto do Anuário Estatístico do Estado de São Paulo. São Paulo, 1988. Mimeografado.

GUIZZARDI FILHO, O.; CONTI, V.L. Produção e disseminação de informações socioeconômicas. Transinformação, Campinas, v.13, n.2, p.43-54, jul./dez. 2001.

LATOUR, B. Ciência em ação - como seguir cientistas e engenheiros sociedade afora. São Paulo: Unesp, 2000.

PORCARO, R.M. Produção de informação estatística oficial na (des)ordem social da modernidade. 2000. 186f. Tese (Doutorado em Ciência da Informação) - Escola de Comunicação, Universidade Federal do Rio de Janeiro e Instituto Brasileiro de Informação em Ciência e Tecnologia, Conselho Nacional de Desenvolvimento Científico e Tecnológico, Rio de Janeiro, 2000.

REPARTIÇÃO DA ESTATISTICA E ARCHIVO DE SÃO PAULO. Relatorio do anno de 1893. Rio de Janeiro, 1894.

REPARTIÇÃO DE ESTATISTICA E DO ARCHIVO DE SÃO PAULO. Annuario estatistico de São Paulo (Brazil) 1902. São Paulo, 1905. $761 \mathrm{p}$.

SÃO PAULO (Estado). Lei n ${ }^{\circ} 185$, de 13 de novembro de 1948. Lex: coletânea de legislação estadual, São Paulo, v.12, p.333-375, 1948.

SENRA, N.C. A coordenação da estatística nacional: o equilíbrio entre o desejável e o possível. 1998. 178p. Tese (Doutorado em Ciência da Informação). Escola de Comunicação, Universidade Federal do Rio de Janeiro e Instituto Brasileiro de Informação em Ciência e Tecnologia, Conselho Nacional de Desenvolvimento Científico e Tecnológico, Rio de Janeiro, 1998.

Um olhar sobre os anuários estatísticos. Ciência da formação, Brasília, v.26, n.1, 1997.

SFEZ, L. Informação, saber e comunicação. INFORMARE - Cad. Prog. Pós-Grad. Ci. Inf., Rio de Janeiro, v.2, n.1, p.5-13, jan./jun. 1996.

VIDAL, D.G. O livro e a biblioteca, o documento e o arquivo na era digital. História da Educação, Pelotas, v.6, n.11, p.53-64, abr. 2002.

WERSIG, G. Information science: the study of postmodern knowledge usage. Information Processing \& Management, v.29, n.2, p.229239, 1993.

Osvaldo Guizzardi Filho: Economista, Chefe da Divisão de Produção de Indicadores da Fundação Seade.

Zilda Pereira da Silva: Socióloga, Analista da Fundação Seade.

Ilma Edna Pereira Sidney: Matemática, Analista da Fundação Seade. 